\title{
EL MARCADOR METADISCURSIVO DE CONTROL DE CONTACTO ¿CIERTO? ¿UN FENÓMENO HISPANOAMERICANO?
}

\author{
THE CONTACT MARKER CIERTO? \\ A HISPANIC AMERICAN PHENOMENON?
}

\author{
Kinga FALUSi \\ Karl-Franzens-Universität Graz \\ kinga.falusi@edu.uni-graz.at \\ orcid: 0000-0002-7159-9431
}

Resumen: Los trabajos que comentan el uso de $\dot{i}$ cierto? y $\dot{i}$ no es cierto? los clasifican generalmente como marcadores que se usan en el español americano actual. Este trabajo investiga la hipótesis según la cual se trataría de un hispanoamericanismo. Para este efecto, se analizan datos diacrónicos provenientes del Corpus del Nuevo diccionario histórico (CDH), que incluye tanto textos europeos como americanos. En concreto, se analizan seis construcciones interrogativas con cierto, utilizadas a partir del siglo xII, y se pone de manifiesto que la evolución diacrónica de ino es cierto? y icierto? se mueve hacia diferentes direcciones: la forma explícita ino es cierto? asoma, por primera vez, en España. Se trata, pues, de una tradición peninsular que surge alrededor del siglo Xvir. De allí pasa al Nuevo Mundo, donde se desarrolla en el siglo xIx la forma corta $\dot{i}$ cierto? Por tanto, la forma abreviada es, efectivamente, un hispanoamericanismo.

Palabras clave: marcador metadiscursivo de control de contacto; diacronía; oralidad; hispanoamericanismo; ¿cierto?, ¿no es cierto?

Abstract: The studies focusing on the use of $\dot{i}$ cierto? and $\dot{i}$ no es cierto? generally classify them as pragmatic markers used in current American Spanish. This paper advances the hypothesis that it is an hispanicamericanism. To this end, it analyses diachronic data from the Corpus del Nuevo diccionario histórico $(\mathrm{CDH})$, which includes both European and American texts. In particular, it studies six interrogative constructions present from the $12^{\text {th }}$ century onwards which revolve around the use of the word cierto. This analysis shows that the diachronic evolution of $\dot{i}$ no es cierto? and $\dot{i}$ cierto? differ: the explicit form, which is $\dot{i}$ no es cierto?, occurs for the first time in Spain and becomes established as a peninsular tradition approximately during the $17^{\text {th }}$ century. From Spain it spreads to the Hispanic American countries, where it develops into the short form $\dot{i}$ cierto? in the $19^{\text {th }}$ century. Therefore, the abbreviated form is indeed an hispanicamericanism.

Keywords: contact markers; diachrony; orality; hispanicamericanism; ¿cierto?, ¿ no es cierto?

Recepción: 24 de septiembre de 2018; aceptación: 25 de febrero de 2020.

D.R. (C) 2021. Nueva Revista de Filología Hispánica Licencia Creative Commons Attribution-NonCommercial (CC BY-NC) 4.0 International 
INTRODUCCIÓN*

Algunos marcadores discursivos, tales como “ ¿sabes?, ¿̨entiendes?, ¿eh?... cumplen una función predominantemente expresivo-apelativa y también fática" (Briz Gómez 1998, pp. 224-225). Para este grupo de marcadores, Briz Gómez utiliza la denominación de marcadores metadiscursivos de control de contacto, por la que optamos en el presente trabajo. En Ortega Olivares (1985 y 1986), éstos aparecen como apéndices comprobativos. Martín Zorraquino y Portolés $(1999$, p. 4188), en el caso de ino?, ¿verdad?, ¿̇eh?, etc., utilizan el término de marcadores conversacionales que, según los autores, son formas sólo parcialmente gramaticalizadas. Sirven para verificar la comprensión, la aceptación y la cooperación del oyente. Se trata, pues, de marcadores que se usan para garantizar o mejorar el contacto entre hablante y oyente. La función fática consiste en "establecer, prolongar o interrumpir la comunicación, para cerciorarse de que el canal de la comunicación funciona... [y] para llamar la atención del interlocutor o confirmar si su atención se mantiene" (Jakobson 1981, p. 356). Asimismo, estos marcadores cumplen una función discursiva de "justificación del yo". Son "fórmulas autorreafirmativas que refuerzan o justifican los razonamientos de los hablantes ante su[s] interlocutor[es]" (Briz Gómez 1998, pp. 224-225).

También el marcador discursivo cierto tiene, entre otras funciones discursivas, la función de control de contacto:

(1) ¿Y no hubieras preferido el pelotón? Porque, al fin y al cabo, esto no es vida, ¿̨ierto? (Antonio Skármeta, El baile de la Victoria, 2003, Chile) ${ }^{1}$.

(2) Es interesante, ¿no es cierto? (Carlos Gorostiza, El puente, 1949, Argentina).

Como vemos en los dos ejemplos, cierto no necesariamente requiere una respuesta por parte del interlocutor. Tiene, en primer lugar, una función fática, que consiste en comprobar si el interlocutor entiende y sigue al hablante. En los últimos años,

* Este estudio no hubiera sido posible sin las sugerencias y comentarios de Martin Hummel y Katharina Gerhalter.

1 Todos los ejemplos extraídos del Corpus del Nuevo diccionario histórico $(\mathrm{CDH})$ se citan en el presente trabajo con su ortografía original. Las cursivas son mías. 
varios autores han dedicado estudios a los marcadores del discurso en los que predominan las funciones de control de contacto. El marcador discursivo isabes? es uno de los marcadores interrogativos quizás más investigados. Ortega Olivares (1985) analiza $\dot{i}$ sabes? junto a $i n o$ ? y $i$ eh? para observar sus funciones sintácticas. Molina (2005) destaca la alta frecuencia de uso de ¿sabes? y Kluge (2011) compara sabes con el inglés you know y con el francés tu sais. Azofra y Enghels (2017), luego de analizar el marcador epistémico sabes desde un punto de vista diacrónico, llegan a la conclusión de que sabes cumple con la función de marcador del discurso "al menos desde los fines del siglo XIX" (p. 125). Por ser los marcadores discursivos de control de contacto (mdcc) menos estudiados, el presente trabajo se propone analizar la diacronía de $\dot{i}$ cierto? y ino es cierto?

La estructura del artículo es la siguiente: en la primera sección presentamos un breve estado de la cuestión; en la segunda, nos dedicamos a la importancia de la posición discursiva en cuanto a la función pragmática de cierto; en la tercera, explicamos las preguntas de investigación, el corpus y la metodología; en la cuarta, analizamos la diacronía de las formas interrogativas con cierto (sin restricción por país o continente); finalmente, la quinta y sexta sección se dedican, respectivamente, a las diacronías peninsular e hispanoamericana.

\section{ESTADO DE LA CUESTIÓN}

Comparando los escasos estudios sobre el mdcc $\dot{i}$ cierto? o $\dot{i}$ no es cierto? con la cantidad de trabajos acerca de los marcadores mencionados en la introducción, podemos constatar que este mdcc es uno de los menos investigados dentro del grupo de los marcadores con la función presentada más arriba. Rabanales y Contreras (1992, p. 681), que parecen ser los primeros en mencionar la función de cierto como marcador discursivo interrogativo, indican que cierto se usa de esta forma en Chile, donde frecuentemente aparece una variante reducida de ¿no es cierto?, a saber, ¿no cierto?? ${ }^{2}$. Igualmente, Christl (1996, p. 130) destaca que las formas ¿ ${ }^{n}$ e es cierto? y ¿cierto? son típi-

${ }^{2}$ El corpus CDH ofrece solamente dos ejemplos, ambos en Colombia. En el corpus PRESEEA encontramos cuatro ejemplos; dos en Chile y dos en Perú. 
cas de Chile y Argentina. Pons y Samaniego (1998) clasifican la construcción copulativa ¿̨no (es) cierto? como "solicitador de aprobación" en el habla culta chilena. Asimismo, concluyen que este mdcc es utilizado, principalmente, por hombres de entre 57 y 75 años (p. 16).

Desde una perspectiva peninsular, Santos Río (2003) registra ciertamente, cierto, cierto que, cierto es que, bien es cierto que, si bien es cierto que, es cierto que, es lo cierto, lo cierto es, por cierto, por cierto que y ¿no es cierto? Por lo que se refiere a este último mdcc, Santos Río señala que puede cumplir una función fática y lo relaciona con la pregunta retórica ¿no?, pero se olvida de mencionar la función fática en la entrada de cierto, es decir, la forma corta icierto? El Diccionario de americanismos (ASALE 2010) registra ¿cierto? en Colombia y Bolivia. En su trabajo sincrónico sobre el español de Santiago de Chile, San Martín Núñez (2011) extrae datos del corpus sociolingüístico de PRESEEA, con el fin de descubrir cuál es el mdcc más frecuente en esa zona. Desde nuestro punto de vista, su conclusión más significativa es el escaso uso del marcador interrogativo de control

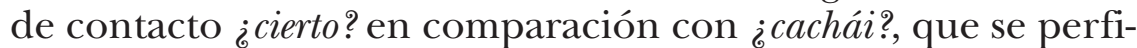
la como el más utilizado en el territorio santiaguino (p. 162). Sin embargo, en un estudio más reciente y parcialmente sociolingüístico sobre los equivalentes funcionales de ¿cachái? Lewis Vergara y San Martín Núñez (2018, p. 308) revelan, entre otras cosas, que ¿cachái? y formas como ¿cierto?, ¿no cierto? y ino eh cierto? se encuentran entre los marcadores de control de contacto más utilizados en el habla santiaguina. Por lo demás, los estudiosos indican que la mayor frecuencia del empleo de las variantes interrogativas de cierto se registra en el grupo socioeconómico medio alto (p. 321).

Aparte de los estudios mencionados, Hummel (2012, p. 96) observa que ni los diccionarios ${ }^{3}$ ni los trabajos más generales sobre el marcador discursivo cierto examinan su uso como marcador fático. Esto se debe, según el autor, a que las investigaciones sobre el tema son principalmente peninsulares. En concreto, los estudios canónicos de Portolés (1998), Martín Zorraquino y Portolés Lázaro (1999), Briz Gómez (1998 y 2009) y Fuentes

${ }^{3}$ En el Diccionario de partículas discursivas del español hallamos entradas solamente con hasta cierto punto y por cierto (que), pero no con las variantes del mdcc cierto. 
Rodríguez (1990, 1990a, 19924 y 2009) se centran en los usos peninsulares y no tienen en cuenta el valor fático de cierto. Sin embargo, las diferentes construcciones con cierto que muestran un valor fático son recursos muy frecuentes en Hispanoamérica (Hummel 2012, p. 97), como indica también nuestro breve repaso bibliográfico anterior. Sobre esta base, Hummel (p. 96) plantea la hipótesis según la cual el marcador fático cierto sería un hispanoamericanismo. Según Hummel (p. 123), el mdcc cierto puede aparecer con las formas icierto? y ino es cierto?; asimismo, hace hincapié en el carácter culto de estas dos construcciones interrogativas, evidente, por ejemplo, en "ponencias académicas" (p. 97) ${ }^{5}$, cuyos expositores pretenden mantener el flujo de la comunicación con la audiencia $(i d$.$) .$

Esta marca de registro también aparece en un trabajo reciente de Nalleli García (2016, p. 33), quien clasifica ¿ino es cierto? como marcador discursivo cortés de negociación frecuente en México. La autora destaca que este mdcc no es exclusivamente un mexicanismo; sin embargo, no indica las otras zonas en las que se utiliza. Añadamos que, en cambio, el marcador chileno ¿cachái? es claramente coloquial, por lo que se opondría, pues,

${ }^{4}$ Estos estudios se refieren a otras funciones discursivas de cierto. Por ejemplo, Fuentes Rodríguez (1992, p. 898) observa una "atractiva complejidad tanto sintáctica como semántica". La autora distingue varios usos y derivados de cierto, al ponerlos en relación con sus funciones semánticas y pragmáticas: adjetivo, Una noticia cierta; atributivo, Si, es cierto; presentador (cuantificador), Ciertas personas vinieron a buscarte, adverbio (sólo en forma de ciertamente), Ciertamente, éste ha sido un mal año. Al respecto, la autora concluye que, en ninguno de los casos, es cierto algo que "apunte a una referencia extralingüística, sino un elemento de la macroestructura del texto" (id.). Es decir, tiene en los cuatro usos una función discursiva. Asimismo, el corpus C-Oral-Rom contiene un solo ejemplo de cierto como signo discursivo independiente que aparece como respuesta afirmativa por un hablante argentino (Hummel 2012, p. 97). Por lo tanto, en el ámbito pragmáticodiscursivo, cierto es polifuncional, y entre las múltiples funciones que cumple, la fática, al parecer, es la menos frecuente. El término de polifuncionalidad, o multifuncionalidad, es complementario al concepto de polisemia: "se trata de definir interrelaciones, que son semánticas en la polisemia, y funcionales en la polifuncionalidad" (Hummel 2012, p. 65).

5 Los resultados preliminares de una investigación de campo de la autora del presente estudio muestran una presencia reducida de las variantes del marcador de control de contacto cierto en el habla culta (ámbito académico) de la Ciudad de México, frente a los marcadores como ino?, isí? ¿verdad?, etc. Esto, por tanto, se contrasta con los resultados de Chile, donde el mdcc cierto es uno de los más frecuentes marcadores de este tipo (LEWIS VERGARA y SAN MARTín NúÑEz 2018). 
a cierto, que probablemente se prefiere en el habla culta. Lewis Vergara y San Martín (2018, p. 321) descubren que las variantes interrogativas de cierto se emplean principalmente en el grupo socioeconómico medio alto. Suponemos que este grupo, debido a la mayor posibilidad de tener una formación académica, tiende a utilizar el lenguaje culto, que eventualmente incluye el uso de las variantes del marcador de control de contacto cierto.

Generalmente, los estudiosos están de acuerdo en que la posición de los marcadores discursivos en el enunciado está relacionada con la función pragmática que cumplen. Por lo que se refiere a la posición discursiva, Briz Gómez (1998, pp. 224225) señala que las funciones discursivas de un marcador varían según aparezcan en posición interior o final. Así, por ejemplo, el marcador discursivo isabes? puede presentarse en ambas posiciones. Veamos dos ejemplos:

(3) Le he dado isabes? muchas vueltas a lo que me dijiste el otro día (Briz Gómez 1998, p. 225).

(4) ¿No estabas de régimen? / pues los dulces engordan, ¿sabes?

En (3), ¿sabes? se encuentra en posición interior del enunciado, donde el marcador tiene la función de reafirmación o justificación ${ }^{6}$. Lewis Vergara y San Martín Núñez (2018, pp. 311312) destacan que también los marcadores ¿no cierto? y ¿cierto? (v.gr. "tener ee ¿̇no cierto? un compañerismo") surgen a menudo en esta posición ${ }^{7}$, en la cual funcionan como estructuradores que ayudan "al hablante a ganar tiempo para planificar su discurso”. Su opinión, con respecto al ejemplo en paréntesis, coincide con la de Rodríguez Muñoz (2009, pp. 90-91), quien asegura que este marcador es sustituible por el marcador de relleno $e h$. Siguiendo con los ejemplos de Briz Gómez (1998), ¿ sabes? frecuentemente aparece en posición final y con un ascenso entonativo final. Según el autor, el marcador $\dot{i}$ sabes? cumple en este caso una función exhortativa, esto es, expresa una petición, un ruego o un mandato (pp. 224-225). En este trabajo, puesto que su propósito es otro, no vamos a comprobar

${ }^{6}$ Más casos de este tipo pueden consultarse en BRIz Gómez 1998, pp. 225-226.

7 En Lewis Vergara y San Martín Núñez (2018, p. 311), las unidades fragmentarias incompletas en las cuales surgen estos marcadores se denominan intersegmentos. 
la intercambiabilidad de marcadores de este tipo, porque para ello haría falta analizarlos, por ejemplo, mediante una sustitución de cierto por otros marcadores de función parecida. Junto a la posición discursiva ${ }^{8}$, Briz Gómez también destaca los rasgos tonales como factores principales que afectan a la función de los marcadores conversacionales, tales como ino?, ¿eh?, ¿entiendes?, etc. Los "rasgos tonales y de intensidad" son capaces de discernir entre los valores de una misma variante en posición final. Así, tomando en cuenta las marcas prosódicas como uno de los rasgos diferenciadores de la función de los mdcc, Briz Gómez distingue claramente los marcadores con función apelativa y con función expresiva fática $(i d$.).

Galué (2002) resalta la importancia de la posición (sin mencionar los rasgos entonativos) de estos marcadores. Según la autora, los marcadores interrogativos tales como iverdad?, ¿entiendes?, o la forma copulativa negativa ¿̇no es cierto?, se ubican frecuentemente al final del segmento discursivo. Asimismo, Galué menciona que, si éstos aparecen en la posición final de los enunciados asertivos, el objetivo del hablante es "enfatizar la veracidad del contenido de su proposición” (p. 39):

(5) mira/ yo estoy preparada para ser abogado/ ¿verdad? / (Galué 2002, p. 40).

En cambio, si se presentan en el interior del enunciado, o entre dos enunciados, "sirven de pausa para marcar la transición", y se convierten, a veces, en muletillas:

(6) Ahora/ si tú me estás pegando contra la pared/ ¿verdad? / yo te estoy dando un término más o menos prudente/ ¿verdad? / pero si tú me estás pegando contra la pared / yo el lunes amanezco allí/ $(i d$.$) .$

En este caso, el hablante utiliza la pausa para organizar sus pensamientos "más que para constatar la atención del interlocutor" (p. 39).

${ }^{8}$ Fuentes Rodríguez (2014) insiste en que en el acto de habla no se comunica con oraciones, sino que se relacionan enunciados y se mantiene, además, una conexión con el interlocutor. Por tanto, en el presente trabajo utilizamos el término de posición discursiva, que se refiere a la posición del marcador en el enunciado del hablante. 
Cortés y Camacho (2005) son los primeros en admitir que en el caso de los marcadores discursivos es importante separar lo textual de lo interactivo. Por tanto, la mayoría de los marcadores pueden cumplir a la vez varias funciones, según se analicen desde una perspectiva interactiva o textual. La perspectiva textual, según los autores, se refiere al discurso oral como "una sucesión progresiva y lineal de segmentos de fonación" (p. 154). Esta visión permite observar cómo el hablante organiza su discurso desde una perspectiva lógico-lingüística (marcador discursivo de cierre del tema, por ejemplo). Sin embargo, desde una perspectiva interactiva, se observa el discurso oral como "fenómeno de conexión -o desconexión- socioafectiva". La visión interactiva se centra en el discurso como acto social e interactivo, en el cual los factores como la modalidad, el registro, el contenido del discurso, etc., influyen en la función de un marcador discursivo (p. 155 $)^{9}$. Así, una función interactiva puede ser, por ejemplo, la empatía o el ofrecimiento del turno al interlocutor. Si observamos las dos variantes del mdcc cierto, notamos que el análisis de Camacho y Cortés podría aplicarse también en un análisis pragmático de las variantes de este marcador:

(7) También es que el retrato es muy viejo, ¿icierto? No tenía usted barba entonces (José Asunción Silva, De sobremesa, 1986, Colombia).

(8) Siendo así, estará usted resuelta a seguirme, ¿no es cierto? -Sí, hijo mío, sí, sería ofender al Todopoderoso, no seguir los pasos del ángel que me envía, porque usted es mi ángel custodio, hijo mío... (Wenceslao Ayguals de Izco, La bruja de Madrid, 1850, España).

En el ejemplo (7), ¿cierto? cumple una función interactiva de constatación del grado de atención del oyente, sin esperar una respuesta de él. Su función secundaria sería un relleno (Cortés y Camacho 2005, p. 157). La variante ino es cierto? en el ejemplo (8) también podría cumplir dos funciones: una interactiva, en la que el hablante intenta ser empático al ofrecer el turno a su interlocutor; otra, secundaria, desde una perspectiva textual, es el cierre del enunciado $(i d$.$) .$

9 Para los ejemplos analizados, véase la sección completa de Cortés y Camacho 2005, pp. 154-161. 
A la luz de las dificultades que surgen de distintas perspectivas y opiniones sobre posiciones y funciones discursivas, nos limitaremos a una clasificación simplificada: posición inicial y posición final (margen derecho del enunciado). Puesto que trabajamos con un corpus escrito, nos faltan factores como el contexto entero y la prosodia. Sin embargo, el objetivo principal del presente trabajo no es el análisis pragmático de las (micro)funciones del mdcc cierto o de sus posibles funciones secundarias, sino su diacronía. Por tanto, en la parte empírica nos centraremos en los datos que se relacionan con la evolución diacrónica de este marcador.

\section{Preguntas de inVESTIGACión, CORPUS Y METOdología}

Resulta curioso que aún no haya estudios diacrónicos bien documentados sobre el mdcc cierto. Sin embargo, las observaciones mencionadas en el estado de la cuestión servirán como punto de partida del presente estudio, en el que trataremos de dar respuesta a las siguientes preguntas: ¿cómo nació y evolucionó la función de marcador discursivo de control de contacto de cierto en la diacronía del español?; ¿cuáles son sus variantes de uso?; ¿hasta qué punto se puede considerar un hispanoamericanismo?

Para la investigación diacrónica del mdcc cierto, hemos elegido la versión 3.1 del Corpus del Nuevo diccionario histórico (CDH) del año 2013, creado por el Instituto de Investigación Rafael Lapesa de la Real Academia Española. El CDH es un corpus que dispone de documentos no solamente peninsulares, sino también de todos los países hispanohablantes de América. Su lematización semiautomática facilita la búsqueda según tipo de palabra, país y autor. Existe también la posibilidad de buscar estructuras concretas bajo la opción de forma, y combinarlas según las preferencias para el análisis. En nuestro caso, la búsqueda por forma nos permitió tener en cuenta las comas y los signos de interrogación que son pertinentes para la función bajo escrutinio.

Está claro que sólo disponemos de textos escritos para el estudio de la diacronía. Sin embargo, algunos ejemplos de este tipo son discursos directos que pretenden reflejar el lenguaje oral, ya sea éste culto o coloquial (Briz Gómez 1998, p. 24; Hummel 2012, p. 291), lo que permite un análisis diacrónico 
de este marcador perteneciente a la oralidad, al menos reflejada en la escritura:

(9) ¡Si nos hubiéramos encontrado hace un mes! Tal vez me habrías amado... Qué felices seríamos, ¿̇cierto? (José Asunción Silva, De sobremesa, 1896, Colombia).

Para tratar las cuestiones de investigación, es imprescindible que la problemática de la oralidad y escritura tenga una representación pertinente en el análisis del marcador discursivo cierto. Por ello, complementamos tal análisis con datos orales del corpus del Proyecto para el estudio sociolingüistico del español de España y de América (PRESEEA). Con el fin de reflejar fielmente la situación actual del mdcc icierto?, en algunos casos consultamos también el Corpus del español del siglo XXI (CORPES XXI), para comparar varias fuentes de datos.

Para el análisis se han seleccionado no solamente las variantes que se encuentran en una posición sintáctica periférica, sino también las formas con que, con el fin de ofrecer una imagen más integral de la evolución del mdcc cierto. Así, las variantes analizadas son las siguientes: ¿Es cierto que?, ¿№ es cierto que?, ¿es cierto? con coma antepuesta ${ }^{10}$, ¿ No es cierto? con coma antepuesta, así como ¿Cierto? (enunciado/ pregunta del interlocutor) y ¿cierto? con coma antepuesta.

\section{LAS CONSTRUCGIONES INTERROGATIVAS CON CIERTO EN EL CORPUS CDH}

En la presente sección, damos cuenta del análisis de la diacronía y de la función de las construcciones interrogativas con cierto en el conjunto de los países hispanohablantes del corpus, sin restricción según país. Primero, presentamos las formas elegidas con cierto; luego, entramos en el análisis diacrónico de estas variantes, para tratar exclusivamente, por último, la evolución diacrónica de la función de mddc de cierto.

10 Con coma antepuesta se detectan en el corpus CDH las ocurrencias en posición final. 
Las estructuras interrogativas con "cierto"

Hemos analizado las siguientes seis variantes que aparecen, o bien al inicio o al final de la unidad discursiva, o bien como enunciado en función de reacción del interlocutor:

\section{TABLA 1}

Posición discursiva de las estructuras con "cierto"

\begin{tabular}{lll}
\hline Inicio & Final & Pregunta \\
\hline ¿es cierto que...? & $\ldots$, ¿ंes cierto? & 6.b. ¿Cierto? (pregunta \\
¿no es cierto que...? & $\ldots$, ¿no es cierto? & hecha por el segundo \\
& $\ldots$, ¿cierto? & hablante). \\
& $\begin{array}{l}\text { 6.a. ¿Cierto? (pregunta } \\
\text { real o retórica). }\end{array}$ \\
\hline
\end{tabular}

La variación surge de la ausencia o presencia del verbo de cópula y de la negación. Podemos observar que $\dot{i}$ Es cierto que...? ${ }_{¿}$ No es cierto que...? aparecen en posición inicial, mientras que ¿es cierto?, ¿no es cierto? y icierto? se encuentran siempre en posición final del enunciado y antecedidas por una pausa (coma o, en algunas ocasiones, punto). ¿Cierto? aparece tanto en posición inicial como en posición final y como enunciado del interlocutor.

La primera variante, la forma iEs cierto que...?, se encuentra al inicio de un enunciado interrogativo copulativo sin negación, cuyo sujeto es una oración completiva introducida por que:

(10) ¿Es cierto que a los arquitectos que concurrieron a la asamblea general no se les permitió explicar el proyecto? (La Nueva Provincia, 5.II.1997, Argentina).

Por tanto, esta variante no es un marcador discursivo, sino que tiene la función de una pregunta real por falta de información.

En el caso de la segunda forma ( ${ }_{i}$ No es cierto que... ?), estamos ante la misma estructura con negación:

(11) ¿No es cierto que es muy lindo? Que se parece a usted... digo, a su padre... (Jacinto de Salas y Quiroga, Claudia, drama en tres actos, España). 
Esta variante se halla también en posición inicial. Puesto que no se encuentra en el margen derecho del enunciado y no funciona independientemente, tampoco es un marcador discursivo. Sin embargo, según se desprende del ejemplo (13), la pregunta con adverbio de negación tiende a usarse como pregunta retórica, para asegurarse de la atención del interlocutor o para pedir su asentimiento. En contraste con la variante (12), en el caso de ${ }_{i}$ No es cierto que...? una respuesta por parte del interlocutor no es obligatoria.

La tercera (..., ¿ es cierto?) es una pregunta sin negación que se encuentra en posición final (margen derecho) antecedida por una pausa:

(12) Los amigos escriben que estás muy bien, ¿̇es cierto? (Juan García Hortelano, El gran momento de Mary Tribune, 1972, España).

Como vemos, la pregunta se hace por falta de certeza y se requiere una afirmación por parte del interlocutor sobre la veracidad de lo dicho, por lo que la variante no equivale a un mdcc. Su función coincide con la de ¿Es cierto que...? que es una pregunta real.

La cuarta variante (..., $\dot{i}$ no es cierto?) es una estructura con negación y cópula en el margen derecho de un enunciado:

(13) Querías comer, ¿no es cierto?... Pos andá, antes de que se acabe el atolito (Ramón Rubín, El callado dolor de los tzotziles, 1948, México).

La pregunta, como vemos, no es una pregunta real, sino que se trata ya de una unidad lingüística autónoma que en este caso sirve para atenuar el enunciado que le precede. Se encuentra en posición final; es más, el hablante continúa hablando sin esperar la respuesta de su interlocutor. Añade un segundo enunciado. Además, ya que se trata de una pregunta retórica -de nuevo con una negación- en posición final, esta variante 4 de la tabla (..., ino es cierto?) cumple con los requisitos de un marcador discursivo de control de contacto, con el cual, en este caso, el hablante pretende atenuar su afirmación. Siendo éste un marcador discursivo, en la siguiente sección analizaremos esta variante desde una perspectiva diacrónica. 
La quinta variante en la Tabla 1 es una variante sin cópula (..., ¿ cierto?) que se encuentra en posición final antecedida por pausa mediante una coma:

(14) Hagamos un recuento: 1964, Cayetana se va con el guerrillero guatemalteco, dejando a su hija con su legítimo padre, ¿cierto? Se van a la guerrilla. Cayetana se ve dividida entre su espíritu justiciero, su odio contra mi padre y esta hija que le sale sobrando (Sophia, El arte de adivinar con las cartas, 1996, Estados Unidos).

De modo parecido al ejemplo (15), la variante (16) aparece justo al final del enunciado. En este caso tampoco se cuestiona la veracidad de lo comunicado, sino que el hablante pretende atenuar su propia afirmación. Por tanto, corresponde a un mdcc. Es una pregunta retórica que forma parte de un monólogo que no requiere respuesta del interlocutor.

Las dos últimas variantes (6.a. y 6.b.) en la Tabla 1 (¿ierto?) se diferencian según se presente la pregunta por falta de credulidad, hecha por el interlocutor (6.b.), o según funcione como pregunta real que pide una respuesta del interlocutor (6.a.). Empecemos con la variante 6.a.:

(15) Mis cogoteros, creo que esta ruina, la Carmelita, ya ha vivido bastante. Pronto Dios la va a matar. ¿Cierto? - ¡Cierto! (Alejandro Jodorowsky, Donde mejor canta un pájaro, 1992, Chile).

Vemos una variante en posición final, puesto que la pausa anterior puede representarse por coma, por punto o incluso por puntos suspensivos. Si no hubiéramos tenido el texto escrito, esta diferencia ortográfica ni siquiera se notaría, por lo cual no desempeña un papel decisivo en la determinación del mdcc. Sin embargo, por la respuesta (;Cierto!) del interlocutor podemos suponer que se trata de una pregunta real, sea ésta por inseguridad, incredulidad o miedo. Por tanto, en el ejemplo (15) ¿Cierto? no es una pregunta retórica que no necesite respuesta del interlocutor. Así, prácticamente, no se puede clasificar como mdcc.

Por lo que se refiere a la variante 6.b. de la Tabla 1, la pregunta no forma parte del discurso del primer hablante; al contrario, se trata de una reacción del interlocutor: 
(16) Peribáñez. Mi amor se agravia de ti.

CASILDA. ¿Cierto?

Peribáñez. Sí

(Lope de Vega Carpio, Peribáñez y el Comendador de Ocaña, 1605, España).

En este diálogo, el marcador discursivo supone una pregunta real hecha por el segundo hablante. Esta intervención viene exigida por la incredulidad de Casilda, quien, como vemos, no cree que el amor de Peribáñez se agravie de ella, por lo cual demanda una confirmación. Ya que se trata de una obra de teatro, sería concluyente, por ejemplo, ver un gesto de desconfianza en el rostro de Casilda. Dado que ¿Cierto? funciona como pregunta real por incredulidad, no se puede clasificar como marcador de control de contacto. Esto podría interpretarse como una forma elíptica de la pregunta “¿Es cierto lo que me dices?"

Según se advierte en las construcciones presentadas, las variantes ¿̇no es cierto? y icierto? en posición final (esté la segunda separada mediante coma o punto), que se refieren a la propia afirmación y aparecen después de ésta, funcionan como mdcc. Por ello, las examinaremos en los siguientes apartados con más detalle.

\section{Análisis cuantitativo de la evolución diacrónica} de las construcciones interrogativas con "cierto"

La Tabla 2 muestra la frecuencia de uso de las variantes con cierto según su construcción sintáctica. Para cada variante, especificaremos en una segunda línea cuántos ejemplos del conjunto de las ocurrencias aparecen con función de control de contacto (mdcc). En las columnas, la frecuencia absoluta en negritas viene seguida, entre paréntesis, de la frecuencia relativa por millón de palabras.

Las gráficas 1 y 2 representan el desarrollo diacrónico de las variantes: primero su uso general; después, sólo su uso como mdcc.

La estructura explícita sin negación en posición inicial $\dot{\zeta}^{E s}$ cierto que... ?aparece en el período que va de 1064 a 1500. La frecuencia relativa en tal período es de 0.06 ejemplos por millón de palabras. Entre 1501 y 1700, la frecuencia relativa indica un 
TABLA 2

Frecuencia absoluta y relativa de las construcciones interrogativas con "cierto" en el corpus CDH (todos los países)

\begin{tabular}{|c|c|c|c|c|c|c|}
\hline Variante & $\begin{array}{l}\text { Posición } \\
\text { discursiva }\end{array}$ & $\begin{array}{l}1064- \\
1500\end{array}$ & $\begin{array}{l}1501- \\
1700\end{array}$ & $\begin{array}{l}1701- \\
1800\end{array}$ & $\begin{array}{l}1801- \\
1900\end{array}$ & $\begin{array}{l}1901- \\
2005\end{array}$ \\
\hline $\begin{array}{l}\text { ¿Es cierto } \\
\text { que? }\end{array}$ & Inicial & $3(0.06)$ & $8(0.08)$ & $4(0.22)$ & 74 (1.44) & $371(1.80)$ \\
\hline$m d c c$ & & - & - & - & - & - \\
\hline $\begin{array}{l}\text { ¿No es cierto } \\
\text { que? }\end{array}$ & Inicial & $\mathbf{0}(0.00)$ & $8(0.08)$ & $7(0.38)$ & $47(0.91)$ & $107(0.52)$ \\
\hline$m d c c$ & & - & - & - & - & - \\
\hline , ¿es cierto? & Final & $\mathbf{0}(0.00)$ & $2(0.02)$ & $2(0.11)$ & 7 (0.14) & $32(0.16)$ \\
\hline$m d c c$ & & $0(0.00)$ & $0(0.00)$ & $0(0.00)$ & $0(0.00)$ & $1(0.005)$ \\
\hline $\begin{array}{l}\text {, ¿̨no es } \\
\text { cierto? }\end{array}$ & Final & $\mathbf{0}(0.00)$ & $1(0.01)$ & $\mathbf{0}(0.00)$ & $65(1.26)$ & $426(2.07)$ \\
\hline$m d c c$ & & $0(0.00)$ & $1(0.01)$ & $0(0.00)$ & $65(1.26)$ & $426(2.07)$ \\
\hline ¿Cierto? & $\begin{array}{l}\text { Inicial, final, } \\
\text { pregunta del } \\
\text { interlocutor }\end{array}$ & $1(0.02)$ & $34(0.34)$ & $2(0.11)$ & $19(0.37)$ & $89(0.43)$ \\
\hline$m d c c$ & & $0(0.00)$ & $0(0.00)$ & $0(0.00)$ & $3(0.06)$ & $10(0.05)$ \\
\hline , ¿cierto? & Final & $\mathbf{0}(0.00)$ & $\mathbf{0}(0.00)$ & $\mathbf{0}(0.00)$ & $8(0.16)$ & $46(0.22)$ \\
\hline$m d c c$ & & $0(0.00)$ & $0(0.00)$ & $0(0.00)$ & $8(0.16)$ & $46(0.22)$ \\
\hline
\end{tabular}

crecimiento ligero de su uso (0.08). En el siglo XVIII, a pesar de las pocas ocurrencias detectadas, la frecuencia relativa $(0.22)$ indica un crecimiento considerable, ya que su uso se triplica. Con respecto al siglo xix, notamos un aumento aún más drástico; la frecuencia relativa es de 1.44, es decir seis veces más frecuente que en el siglo anterior. En el siglo xx, también observamos un leve incremento (1.80). Por tanto, según los datos del corpus, el uso de esta variante se ha vuelto cada vez más frecuente.

La segunda construcción sintáctica en la Tabla 2 es la forma con negación $\dot{i}$ No es cierto que... ?, la cual, como mencionamos, posee un carácter retórico. ¿№ es cierto que...? surge, por primera vez, entre 1501 y 1700 , con una frecuencia relativa de 0.08 . En el siglo XviII, la frecuencia relativa $(0.38)$ muestra un aumento cuádruple de su uso en comparación con el 


\section{GrÁFICA 1}

Diacronía de todas las variantes con "cierto"

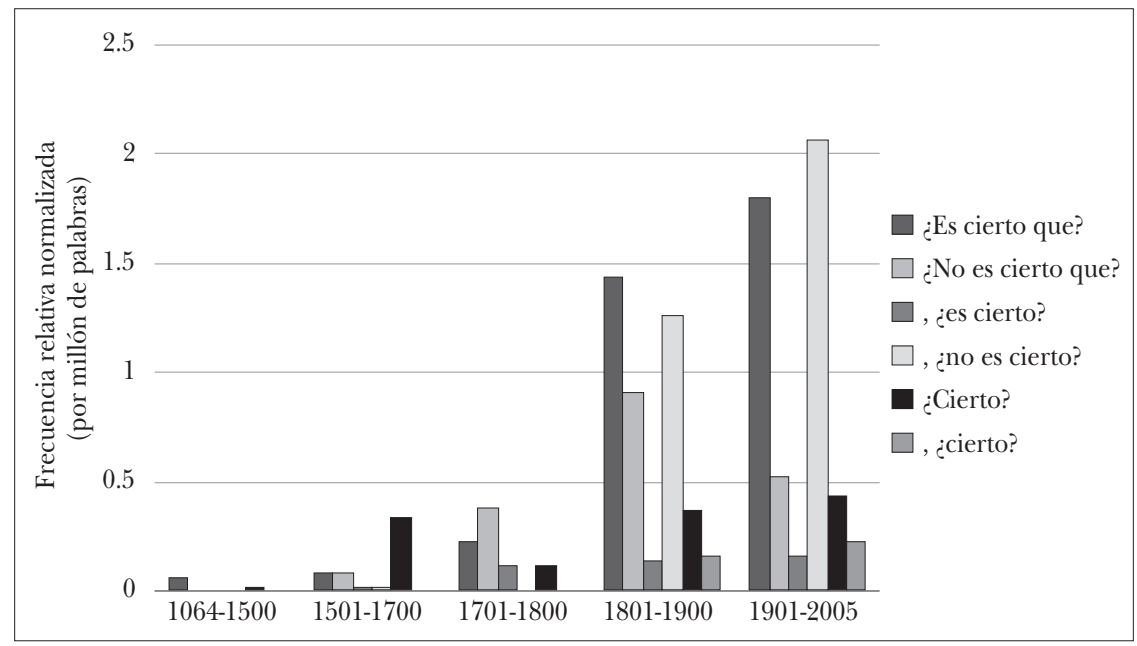

\section{GRÁFICA 2}

Diacronía de los mdcc

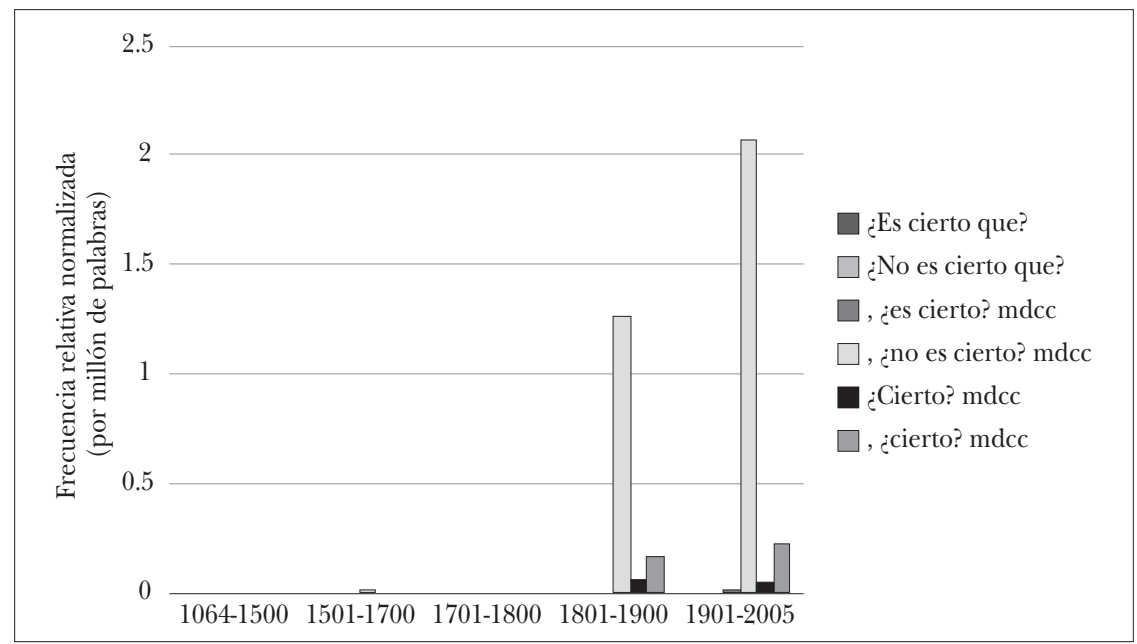

Nueva Revista de Filología Hispánica (NRFH), LXIX, 2021, núm. 1, 43-77

ISSN 0185-0121; e-ISSN 2448-6558; DOI: 10.24201/nrfh.v68i1.3708 
período anterior. En el siglo xIx, el empleo de esta estructura aumenta aún más; la variante aparece casi una vez (0.91) por cada millón de palabras. Curiosamente, en el último siglo la frecuencia relativa es solamente de 0.52 , lo que significaría, pues, que la estructura $\dot{i}$ No es cierto que...? hoy se usa menos que, por ejemplo, en el siglo xIx. Sin embargo, esta reducción se explica con un simple cambio de posición en el enunciado; vemos que a partir del siglo xix esta estructura aparece en posición final, funcionando ya como mdcc.

Para la tercera variante, ¿es cierto? sin negación y en posición final, el corpus ofrece escasos ejemplos. Las primeras ocurrencias surgen en el período entre 1501 y 1700 con una frecuencia relativa de 0.2 . Sin embargo, en el siglo XVIII, la frecuencia relativa es de 0.11 , es decir cinco veces superior a la registrada en la época entre 1501 y 1700 . En el siglo xIx, también notamos un ligero crecimiento de las ocurrencias con la forma ies cierto?; la frecuencia relativa es de 0.14 . La situación es semejante en el siglo $\mathrm{xx}$, en el que se documenta una frecuencia relativa de 0.16 . Diacrónicamente, la estructura ies cierto? parece seguir el mismo tipo de expansión que la construcción ¿es cierto que...? pero con retraso y moderación. La interpretación de ¿es cierto? como reducción económica de la construcción plena ies cierto que? podría explicar estos datos, puesto que ambas son preguntas reales.

La pregunta con negación en posición final (¿no es cierto?) es interesante en muchos aspectos. En la sección anterior mencionamos que i̇no es cierto? en posición final es un mdcc. Según los datos, esta variante aparece en el corpus entre 1500-1700, por lo que se posiciona como el primer mdcc que surge con cierto. A partir del siglo xIx, su frecuencia de uso crece de forma excepcional al aparecer 1.26 veces por millón de palabras, al paso que en el siglo xx la frecuencia relativa llega a 2.07 ejemplos por cada millón de palabras. En este siglo, tanto la frecuencia absoluta como la frecuencia relativa sugieren que, de las seis estructuras analizadas, ésta es la variante más utilizada por los hispanohablantes. Si tenemos en cuenta que la negación incluye casi automáticamente una función retórica, podemos interpretarla como indicadora de la función privilegiada. De hecho, vemos claramente que la función de control de contacto arranca con esta variante. Sin embargo, si es cierto que la función retórica predomina, podremos luego explicar la función de control de contacto, que se observa en ejemplos 
recientes como atenuación o debilitación de una función básicamente retórica.

La variante sin negación (cf. supra apartado anterior), que puede ocupar posición inicial o final, o incluso darse como enunciado (¿Cierto?), aparece relativamente pronto; de hecho, en la época entre 1064 y 1500. De este período, el corpus ofrece solamente un ejemplo; pero notamos un aumento repentino en el siguiente: entre 1501 y 1700 la frecuencia relativa (0.34) indica que en esta época la forma ¿Cierto? disfrutaba de mayor popularidad que, por ejemplo, un siglo antes o después. En el siglo XvIII, efectivamente, la frecuencia de su uso cae a 0.11 ocurrencias por millón de palabras. Sin embargo, a partir del siglo xIx, aumenta su frecuencia relativa, para alcanzar su máximo en el siglo $\mathrm{xx}(0.43)$.

La evolución de la pregunta retórica sin negación en posición final (icierto?) es prácticamente la misma que la de la forma ¿̇no es cierto? en posición final; si tomamos en consideración que ambas formas funcionan generalmente como mdcc, esta coincidencia no es aleatoria. La forma ¿cierto? no aparece en el corpus hasta el siglo xIx, que cuenta con una frecuencia relativa de 0.16 , es decir ocho veces menor que ino es cierto? en posición final. En el siglo xx su frecuencia relativa es de 0.22, cifra nueve veces menor que la de la forma con negación. Esto se debe, probablemente, a que la escritura tiende a utilizar las formas explícitas más que el habla oral ${ }^{11}$.

Después de haber presentado la diacronía de las construcciones, a continuación, realizaremos un análisis diacrónico de las variantes del mdcc cierto.

\section{La evolución diacrónica del mdcc "cierto"}

La Tabla 2 presentada en el apartado anterior muestra por separado las funciones de mdcc para cada una de las construcciones. Cronológicamente, la primera variante que aparece en la Tabla 2 como mdcc es la variante negativa $\dot{i}$ no es cierto?, antecedida por una pausa -correspondería al alemán nicht wahr?, y al inglés isn't it? Este mdcc aparece, por primera vez, en el siglo XVII -las atestaciones se citarán según su ocurrencia en los apartados

11 En el corpus PRESEEA domina la estructura corta ¿cierto? frente a la estructura explícita de ïno es cierto? 
correspondientes a Europa y América. Paralelamente, aparecen las primeras ocurrencias con la estructura retórica antepuesta con negación ${ }_{i}$ No es cierto que... ? Esta estructura surge en siete ocasiones en el siglo XVII, mientras que el mdcc ¿no es cierto? (posición final) aparece solamente una vez en este siglo, lo que confirma una vez más la suposición según la cual el mdcc ¿̇no es cierto? habría nacido directamente de la estructura retórica interrogativa negativa antepuesta $\dot{i}$ No es cierto que?, con la que ha convivido hasta el día de hoy. Por tanto, en el siguiente diagrama mostramos la evolución de este mdcc:

\section{Diagrama 1}

Proceso de evolución del mdcc "cierto"
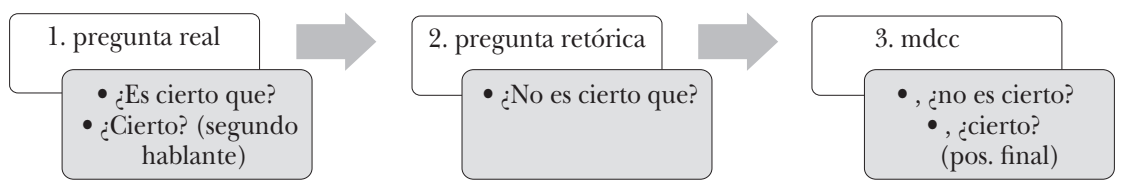

Podemos confirmar nuevamente que la posición discursiva tiene un papel decisivo en el asentamiento de esta función. Al moverse al margen derecho del enunciado, surge el uso como mdcc.

Siguiendo la evolución diacrónica de ¿̇no es cierto?, notamos que, en el siglo XVIII, el corpus no ofrece ocurrencias con este mdcc. Sin embargo, en el siglo xix, el número de los ejemplos aumenta súbitamente a 65 ocurrencias con este mdcc.

En el siglo xx hay un cambio aún más drástico; en total, encontramos 426 ocurrencias con el mdcc ino es cierto? Con base en su frecuencia relativa, podemos concluir que, en este caso, se trata de la forma interrogativa más difundida con cierto, que triunfa incluso sobre la estructura ino es cierto que? en posición inicial.

Diacrónicamente, el segundo marcador que aparece en el corpus es el mdcc icierto? sin cópula. Este marcador, que constituye la forma interrogativa más reciente, aparece por primera vez en el siglo xix, en el que hallamos un total de 11 ejemplos (8 con ¿cierto? y 3 con $\underset{i}{ }$ Cierto?) con la función mencionada, número que parece escaso si se compara con su forma explícita con negación ¿̇no es cierto? en este mismo siglo (65 ocurrencias). En lo que se refiere al siglo xx, el abismo 
entre las dos formas es aún más sobresaliente; encontramos un total de 56 ocurrencias ( 46 con $\dot{i}$ cierto? y 10 con $\dot{i}$ Cierto?) de la forma icierto?, frente a las 426 ocurrencias del mdcc ¿no es cierto?

Destacamos que, con un corpus oral, hubiéramos obtenido resultados distintos en los que, probablemente, predominaría la forma corta icierto? Por ejemplo, el corpus PRESEEA ha dado en total 291 ocurrencias con la forma ¿cierto?, frente a las 6 ocurrencias con la forma explícita con negación ¿no es cierto? Por tanto, suponemos que, en términos de reconstrucción diacrónica a partir de datos orales actuales, los textos literarios en el corpus que intentan imitar el habla oral han optado por la versión algo más formal y explícita ¿̇no es cierto? frente a la variante más informal ¿icierto?

En el siglo Xx, aparecen unas pocas ocurrencias como mdcc con las formas $i$ Cierto? y ies cierto?, ambas en posición final. En el caso de $i$ Cierto?, como ya mencionamos, se trata, simplemente, de un cambio en la puntuación que en el habla oral ni siquiera se notaría; el autor decidió poner un punto en vez de coma entre el enunciado y el mdcc cierto: "Esto está bien así, ¿cierto?" $\rightarrow$ "Esto está bien así. ¿̨Cierto?".

Para determinar si el grupo bajo escrutinio es un hispanoamericanismo, conviene separar los datos según sean europeos o americanos. A continuación, observaremos la evolución diacrónica de estas formas en España.

\section{ANÁlisis diacrónico DEL MDCG CIERTO EN EsPaÑa}

En este apartado, analizamos la diacronía de las formas interrogativas con cierto en la Península Ibérica, con atención especial a las primeras ocurrencias con la función de mdcc. En los siguientes subapartados ofrecemos, respectivamente, los datos sacados del corpus con todas las formas y una ponderación diacrónica de la función de mddc de cierto en la Península Ibérica.

Aspectos generales cualitativos y cuantitativos de la diacronía peninsular

En la Tabla 3, presentamos las frecuencias absoluta y relativa de las construcciones interrogativas con cierto en el español 
peninsular, a partir del siglo xi. Debajo de cada construcción se señalan las ocurrencias como mdcc.

\section{TABLA 3}

Frecuencia absoluta y relativa de las construcciones interrogativas con "cierto" en España

\begin{tabular}{|c|c|c|c|c|c|c|}
\hline Variante & $\begin{array}{l}\text { Posición } \\
\text { discursiva }\end{array}$ & $\begin{array}{l}1064- \\
1500\end{array}$ & $\begin{array}{l}1501- \\
1700\end{array}$ & $\begin{array}{l}1701- \\
1800\end{array}$ & $\begin{array}{l}1801- \\
1900\end{array}$ & $1901-2005$ \\
\hline $\begin{array}{l}\text { ¿Es cierto } \\
\text { que...? }\end{array}$ & Inicial & $3(0.06)$ & $7(0.08)$ & $4(0.32)$ & $57(1.42)$ & $236(1.89)$ \\
\hline$m d c c$ & & - & - & - & - & - \\
\hline $\begin{array}{l}\text { ¿No es cierto } \\
\text { que...? }\end{array}$ & Inicial & $\mathbf{0}(0.00)$ & $2(0.02)$ & $7(0.56)$ & $29(0.72)$ & $41(0.33)$ \\
\hline$m d c c$ & & - & - & - & - & - \\
\hline , ¿es cierto? & Final & $0(0.00)$ & $2(0.02)$ & $2(0.16)$ & $3(0.07)$ & $16(0.13)$ \\
\hline$m d c c$ & & $0(0.00)$ & $0(0.00)$ & $0(0.00)$ & $0(0.00)$ & $0(0.00)$ \\
\hline $\begin{array}{l}\text {, ¿no es } \\
\text { cierto? }\end{array}$ & Final & $\mathbf{0}(0.00)$ & $1(0.01)$ & $\mathbf{0}(0.00)$ & $36(0.90)$ & $118(0.94)$ \\
\hline$m d c c$ & & $0(0.00)$ & $1(0.01)$ & $0(0.00)$ & $36(0.90)$ & $118(0.94)$ \\
\hline ¿Cierto? & $\begin{array}{l}\text { Inicial, final, } \\
\text { pregunta del } \\
\text { interlocutor }\end{array}$ & $1(0.02)$ & $34(0.40)$ & $2(0.16)$ & $6(0.15)$ & $7(0.06)$ \\
\hline$m d c c$ & & $0(0.00)$ & $0(0.00)$ & $0(0.00)$ & $0(0.00)$ & $3(0.02)$ \\
\hline , ¿cierto? & Final & $\mathbf{0}(0.00)$ & $\mathbf{0}(0.00)$ & $0(0.00)$ & $\mathbf{0}(0.00)$ & $2(0.02)$ \\
\hline$m d c c$ & & $0(0.00)$ & $0(0.00)$ & $0(0.00)$ & $0(0.00)$ & $2(0.02)$ \\
\hline
\end{tabular}

Si seguimos el orden diacrónico, observamos que dos de las variantes sin negación, ¿Es cierto que? y ¿Cierto?, aparecen documentadas entre 1064 y 1500. Ambas se encuentran en posición oracional inicial. La primera de ellas asoma por primera vez, según el corpus, a mitad del siglo xv:

(17) Ruy Díaz, ¿es çierto que el Rey mi señor me enbía a mandar esso que vos me dezís? (Anónimo, Crónica de Don Álvaro de Luna, 1453, España).

En el período entre 1064 y 1500 , la frecuencia relativa es de 0.06 . Aumenta (0.08) entre 1501 y 1700. En el siglo XVIII, 
la frecuencia relativa de 0.32 indica un aumento notable en comparación con los siglos anteriores. Con respecto al siglo xIx, con base en la frecuencia relativa (1.42), podemos ver que esta estructura explícita es la forma más usada. En el siglo $\mathrm{xx}$, vemos una frecuencia relativa de 1.89 , lo que significa que esta variante sigue siendo la más extendida incluso en este siglo.

La segunda construcción (¿̨Cierto? como enunciado autónomo) aparece también relativamente temprano en comparación con las otras variantes:

(18) Celestina. De Areúsa, hija de Eliso.

PÁrmeno. ¿Cierto?

Celestina. Cierto.

(Fernando de Rojas, La Celestina. Tragicomedia de Calisto y Melibea, 1499-1501, España).

En el siglo xv, este ejemplo es el único. Pero, si observamos el período entre 1501 y 1700 , vemos que la forma se convierte en la construcción más usada, con una frecuencia normativa de 0.40. Cabe mencionar que, en todos los casos, es el segundo hablante quien hace la pregunta como una reacción ante el aserto de su interlocutor y no como mdcc en posición final. A partir del siglo XVIII, hay un descenso sucesivo de ${ }_{i}$ Cierto? (0.16). La situación es parecida en el siglo XIX, ya que la frecuencia relativa es de 0.15 ejemplos por millón de palabras. En el siglo xx, la frecuencia relativa (0.06) indica que, hoy en día, esta fórmula se usa escasamente en España.

En el período que va de 1501 a 1700 , surgen tres nuevas formas. La primera, ¿no es cierto que?, aparece a principios del siglo XVII ${ }^{12}$ :

12 Uno de los evaluadores anónimos de este trabajo señala que en el lenguaje jurídico de España es muy frecuente el uso de las preguntas retóricas como ${ }_{\dot{b}}$ No es cierto que...? y $\dot{i}$ No es menos cierto que... ? En efecto, al revisar los ejemplos peninsulares en el corpus $\mathrm{CDH}$ hemos encontrado dos ejemplos con la pregunta ¿No es menos cierto que...? En el lenguaje jurídico también hay otra variante: ¿No es más cierto que... ? Sin embargo, Hidalgo Navarro y VILlalba IbÁÑEz (2016, p. 222) subrayan que ésta representa ya una forma envejecida en la fase de interrogatorio y que puede ser difícil de entender si no se conoce el lenguaje jurídico. 
(19) Infant. La mujer que quiere a dos, ¿ no es cierto que ofende al uno? (Guillén de Castro, Comedia del conde Alarcos, 1602, España).

La frecuencia de uso de la forma en este siglo es relativamente baja, puesto que (19) es el único ejemplo que encontramos. A partir del siglo xviII, la frecuencia de uso (0.56) de esta variante aumenta. Lo mismo ocurre en el siglo xix; la frecuencia relativa sube a un 0.72 . No obstante, en el siglo $\mathrm{xx}$, el uso de esta construcción se reduce a la mitad (0.33). Como ya hemos mencionado líneas arriba, esto se debe, probablemente, a un reemplazo gradual por la variante ¿no es cierto? en posición final.

La forma ¿no es cierto? en posición final después de pausa aparece, por primera vez, a finales del siglo XvII:

(20) D. Pedro. Pues yo lo digo, ¿no es cierto? (Agustín Moreto, El parecido en la Corte, 1695, España).

En este siglo, el corpus solamente proporciona un ejemplo. En el siglo XVIII, ni siquiera encontramos ocurrencias con esta variante, lo que confirmaría nuestra suposición según la cual la forma retórica más frecuente hasta el siglo xix es la estructura ¿no es cierto que? en posición inicial.

No obstante, en el siglo xix, encontramos 36 ejemplos con la estructura negativa en posición final; la frecuencia relativa (0.90) sugiere que la pregunta ¿no es cierto? en tal posición se utiliza en este siglo con mayor asiduidad que la estructura i $\mathrm{No}$ es cierto que? (0.72), a la cual fue reemplazando gradualmente. En el siglo xx, el corpus ofrece incluso 118 ejemplos en España con esta construcción. Como podemos ver, con base en la frecuencia relativa (0.94), esta variante muestra una tendencia creciente a lo largo de los siglos. Parece ser la segunda pregunta más frecuente con cierto en España.

Por último, mencionamos la forma interrogativa sin negación ¿cierto? que se encuentra en el margen derecho del enunciado. Aparece relativamente tarde en España, de hecho, en el siglo XX:

(21) Oh, Pablo, qué encantador... Hemos conversado mucho, mucho. Es una persona inteligente, ¿cierto? Más inteligente que el nivel medio de los españoles, creo (Juan García Hortelano, El gran momento de Mary Tribune, 1972, España). 
Puesto que aparece solamente dos veces en el corpus, suponemos que en el habla cotidiana de España la forma está prácticamente en desuso ${ }^{13}$.

\section{La evolución diacrónica del mdcc "cierto" en España}

La función de cierto como mdcc aparece en España, por primera vez, en el siglo XVII (solamente una ocurrencia), en forma de pregunta explícita con negación (¿no es cierto?) en posición final. La frecuencia de las ocurrencias con ino es cierto? en posición final y la frecuencia de su función como mdcc coinciden en todos los siglos. A partir de ello, podemos concluir que la forma ¿no es cierto? incluye automáticamente la función de mdcc -para la diacronía completa de esta forma, véase el subapartado anterior. Sin embargo, esta variante se utiliza escasamente en España hasta el siglo xıx; antes, esta pregunta retórica se había mantenido en la posición inicial del enunciado, por lo que no ejercía la función de mdcc. Así, la estructura retórica dominante hasta esta época es la forma inicial de ${ }_{\dot{i}}$ No es cierto $q u e .$. ? A partir del siglo xix, observamos que el uso en forma de mdcc aumenta y parece reemplazar la forma inicial. Por tanto, puede colegirse que, en el español peninsular actual, la forma de mdcc ( $i$ no es cierto? final) se usa con mayor frecuencia que la simple pregunta retórica ( ${ }_{i}$ No es cierto que... ?). En este contexto, resaltamos que la negación es, sin duda, el indicador de la función retórica de cierto.

En el siglo xx, surge la variante abreviada, el mdcc $\dot{i}$ cierto? en posición final, es decir trescientos años más tarde que el mdcc ¿no es cierto? La variante corta difiere de la forma con negación al disponer de diferentes funciones; si observamos la variante $i$ Cierto? (enunciado, pausa marcada mediante un punto), la frecuencia de esta estructura no coincide con la frecuencia de su función de mdcc. En lo que se refiere a su difusión en la Península Ibérica, puesto que esta forma aparece solamente en dos ocasiones durante los seis siglos (más tres con la de ¿Cierto?, cuya pausa, antes de enunciarse, está señalada por un punto), puede afirmarse que el uso de la variante abreviada

13 Según uno de los revisores anónimos, al igual que las preguntas retóricas ¿no es cierto que...? y ¿no es menos cierto que...? también el marcador discursivo iccierto? se emplea en el lenguaje jurídico de España. 
¿cierto? como mdcc no es inherente a la Península Ibérica, lo que podría explicarse con la sustitución de esta variante por las preguntas ¿ $n o$ ? y iverdad?, más comunes entre sus hablantes ${ }^{14}$.

\section{ANÁLISIS DIACRÓNICO DEL MDCG CIERTO \\ EN la AmÉrica hispanoHablante}

$\mathrm{Al}$ igual que con el apartado anterior, comenzaremos éste con un análisis cuantitativo y cualitativo general. Luego, nos centramos en la diacronía de la función de mdcc.

Aspectos generales cualitativos y cuantitativos de la diacronía americana

La Tabla 4 ofrece datos cuantitativos sobre la frecuencia con que las formas interrogativas con cierto aparecen en una serie de ocurrencias propias de la América hispanohablante:

\section{TABLA 4}

Frecuencia absoluta y relativa de las construcciones interrogativas con "cierto" en Hispanoamérica

\begin{tabular}{|c|c|c|c|c|c|c|}
\hline Variante & $\begin{array}{l}\text { Posición } \\
\text { discursiva }\end{array}$ & $\begin{array}{l}1064- \\
1500\end{array}$ & $\begin{array}{l}1501- \\
1700\end{array}$ & $\begin{array}{l}1701- \\
1800\end{array}$ & $\begin{array}{l}1801- \\
1900\end{array}$ & $1901-2005$ \\
\hline $\begin{array}{l}\text { ¿Es cierto } \\
\text { que...? }\end{array}$ & Inicial & $0(0.00)$ & $1(0.08)$ & $\mathbf{0}(0.00)$ & $17(1.50)$ & $135(1.67)$ \\
\hline$m d c c$ & & - & - & - & - & - \\
\hline $\begin{array}{l}\text { ¿No es cierto } \\
\text { que...? }\end{array}$ & Inicial & $\mathbf{0}(0.00)$ & $6(0.47)$ & $0(0.00)$ & $18(1.58)$ & $66(0.81)$ \\
\hline$m d c c$ & & - & - & - & - & - \\
\hline , ¿es cierto? & Final & $0(0.00)$ & $0(0.00)$ & $0(0.00)$ & $4(0.35)$ & $16(0.20)$ \\
\hline
\end{tabular}

${ }^{14}$ Según el corpus $\mathrm{CDH}$, en el siglo xx, la frecuencia relativa en posición final de $\dot{i}$ verdad? es de 5.88 , y la de $\dot{i} n o$ ?, de 6.72 . Si se advierte que la frecuencia de $i$ cierto? es de 0.16 en el siglo $\mathrm{xx}$, se confirma su uso marginal en comparación con estos mdcc.

15 El siglo XviII constituye la sección más reducida en el corpus $\mathrm{CDH}$, lo cual explica por qué no hay ninguna documentación. La base textual es insuficiente para ser representativa. 
TABLA 4

Frecuencia absoluta y relativa de las construcciones interrogativas con "cierto" en Hispanoamérica (concluye)

\begin{tabular}{|c|c|c|c|c|c|c|}
\hline Variante & $\begin{array}{l}\text { Posición } \\
\text { discursiva }\end{array}$ & $\begin{array}{l}1064- \\
1500\end{array}$ & $\begin{array}{l}1501- \\
1700\end{array}$ & $\begin{array}{l}1701- \\
1800\end{array}$ & $\begin{array}{l}1801- \\
1900\end{array}$ & $1901-2005$ \\
\hline$m d c c$ & & $0(0.00)$ & $0(0.00)$ & $0(0.00)$ & $0(0.00)$ & $0(0.00)$ \\
\hline $\begin{array}{l}\text {, ¿ंno es } \\
\text { cierto? }\end{array}$ & Final & $\mathbf{0}(0.00)$ & $\mathbf{0}(0.00)$ & $\mathbf{0}(0.00)$ & $29(2.55)$ & $308(3.80)$ \\
\hline$m d c c$ & & $0(0.00)$ & $0(0.00)$ & $0(0.00)$ & $29(2.55)$ & $308(3.80)$ \\
\hline ¿Cierto? & $\begin{array}{l}\text { Inicial, final, } \\
\text { pregunta del } \\
\text { interlocutor }\end{array}$ & $\mathbf{0}(0.00)$ & $0(0.00)$ & $0(0.00)$ & $13(1.14)$ & $82(1.01)$ \\
\hline$m d c c$ & & $0(0.00)$ & $0(0.00)$ & $0(0.00)$ & $3(0.30)$ & $7(0.10)$ \\
\hline , ¿cierto? & Final & $\mathbf{0}(0.00)$ & $\mathbf{0}(0.00)$ & $0(0.00)$ & $8(0.70)$ & $44(0.54)$ \\
\hline$m d c c$ & & $0(0.00)$ & $0(0.00)$ & $0(0.00)$ & $8(0.70)$ & $44(0.54)$ \\
\hline
\end{tabular}

Siguiendo el orden diacrónico de las formas, notamos que las primeras ocurrencias se divisan en el período entre 1501 y 1700. Casi paralelamente, aparecen en el corpus dos de las seis estructuras, ambas explícitas y en posición inicial del enunciado, una sin y otra con negación. Sorprende que la primera de ellas en manifestarse sea la forma con negación y que, además, se use con mayor frecuencia que la variante sin negación:

(22) Beltrán. Pues si honor puede ganar quien nació sin él, ¿̨no es cierto que, por el contrario, puede, quien con él nació, perdello? (Juan Ruiz de Alarcón, La verdad sospechosa, 1619-1620, México).

Con base en la frecuencia relativa (0.47), suponemos que el uso de esta pregunta retórica era común en el español americano del siglo XVII. En el siglo XVIII, en cambio, no encontramos ningún ejemplo. En el siglo XIx, la frecuencia relativa (1.58) muestra un aumento notable en comparación con el siglo XVII. Sin embargo, en el siglo $\mathrm{xx}$, la frecuencia relativa de 0.81 apunta a una disminución de uso de ${ }_{\dot{C}}$ No es cierto que...?

Poco después, aparece en el corpus la variante sin negación. Esto, naturalmente, va en contra de la hipótesis según la cual 
la estructura negativa retórica se desarrolla a partir de la forma sin negación. Sin embargo, puesto que entre las fechas en que se registra el surgimiento de ambas formas hay solamente 30 años de diferencia, pensamos que, en el caso de la aparición más temprana de la forma con negación, se trata de una casualidad:

(23) Sólo pregunto: ¿es cierto que llamando al Rey, a tu mandado vendrá luego? (Pedro de Solís y Valenzuela, El desierto prodigioso y prodigio del desierto, 1650, Colombia).

Éste es el único ejemplo que encontramos en el siglo Xviı con la forma ¿Es cierto que... ? En el siglo XviII, no encontramos ninguna ocurrencia. En el siglo xix, el corpus ofrece en total 17 ocurrencias con esta variante, lo que casi coincide con la forma anterior en el mismo siglo. En cuanto al siglo xx, la frecuencia relativa (1.67) indica que esta forma se utiliza hoy más que, por ejemplo, ¿es cierto? en posición final.

Al igual que en el caso de España, a partir del siglo xıx, podemos observar un aumento súbito de las construcciones interrogativas con cierto. En este siglo, el corpus ofrece ocurrencias para todas las estructuras presentadas en la tabla. Destacamos que estas estructuras surgen casi al mismo tiempo. Así, según el orden diacrónico, la tercera forma que aparece es la variante sin negación con cópula en posición final:

(24) Duque.-Jorge, ¿̨es cierto? (Fernando Calderón, Hermán, o la vuelta del cruzado, 1841, México).

En el siglo xix, la frecuencia relativa (0.35) muestra que esta variante, en comparación con las otras, se utilizaba poco. En el siglo $\mathrm{xx}$, la frecuencia relativa es solamente de 0.20 . Le sigue la estructura retórica con negación en posición final:

(25) Yo sola bastaré siempre a tu corazón, ¿̨no es cierto, amor mío? (Gertrudis Gómez de Avellaneda, Dos mujeres, 1842, Cuba).

En el siglo xIx, la frecuencia relativa (2.55) indica que se trata de una variante asiduamente empleada. Se advierte, por tanto, que en la América hispanohablante ésta es la forma con la frecuencia relativa más alta durante el siglo xix. En el siglo $\mathrm{xx}$, el corpus ofrece aún más ejemplos; por consiguiente, la 
frecuencia relativa alcanza el 3.80 de ocurrencias por millón de palabras.

Las últimas variantes en manifestarse son las formas abreviadas sin negación. La variante separada por un punto antepuesto aparece en el siglo xix:

(26) ...Que ninguno te daría más de treinta y cinco. $\mathrm{D}^{\mathrm{a}}$. Ser.

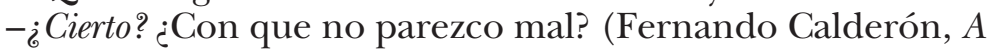
ninguna de las tres, 1845, México).

En el siglo XIX, su frecuencia relativa (1.14), en comparación con las otras en este siglo, se muestra algo reducida, y en el siglo xx, su frecuencia relativa es aún menor (1.01). Con base en estos datos, se desprende que, actualmente, la frecuencia de uso para esta forma continúa en franco descenso $^{16}$. Notemos que en el ejemplo (27) la forma representa una pregunta real hecha por el interlocutor por falta de información o credulidad. Sin embargo, recordemos que en el apartado anterior hemos explicado que la función de esta forma varía según aparezca en el discurso del primer interlocutor al final de su propio enunciado o como pregunta real hecha por el segundo hablante. Así, estos datos se refieren solamente a la variante $i$ Cierto? con un punto antepuesto y no a la variante de $\dot{i}$ cierto? con una pausa antepuesta, señalada por una coma.

La forma abreviada icierto? en posición final, con pausa señalada por una coma, es diacrónicamente la última en aparecer:

(27) Nos las vas a leer dentro de un rato, ¿̇cierto?... Si tú supieras que he pasado hoy un mal día pensando en ti, con la idea fija de que estabas enfermo... (José Asunción Silva, De sobremesa, 1896, Colombia).

Sobre la base de la frecuencia relativa de 0.70 , resulta que la forma retórica sin negación no se utiliza tan a menudo si la comparamos, por ejemplo, con la de negación. En el siglo xx, la frecuencia relativa es solamente de 0.54 , menor aún que la documentada para el siglo anterior. No deja de resultar interesante que, en tanto que el uso de la pregunta retórica negativa

${ }^{16}$ En contraste, ¿̇verdad? muestra un aumento súbito en la frecuencia relativa de uso en el siglo xx, según datos del $\mathrm{CDH}$. 
da muestras de intensificarse a través de los siglos, la forma corta sin negación, en cambio, se emplee cada vez menos.

\section{La evolución diacrónica del mdcc "cierto" en América}

De la Tabla 4 se desprende que la función de mdcc surge en América en el siglo xix. La primera variante con esta función aparece en forma de un marcador discursivo explícito con negación (cf. supra ej. 22). En la misma Tabla 4 hemos visto que las ocurrencias con su función como mdcc y el número total de los ejemplos con esta forma (¿no es cierto? en posición final) coinciden. Por tanto, podemos concluir que, también en América, ¿̇no es cierto? en posición final después de pausa funciona exclusivamente como mdcc. Su carácter monofuncional se afirma, igualmente, en el siglo xx: los 302 ejemplos encontrados con esta forma cumplen la función de mdcc -la diacronía completa de esta forma se halla en el subapartado anterior. En el español americano, en contraste con el de España, el mdcc i ino es cierto? siempre ha sido, desde su primera aparición, la variante más extendida; lo mismo ocurre con su variante retórica en posición inicial ¿̇no es cierto que...? Así pues, en América dominan las variantes con negación ¿no es cierto? (en posición inicial como pregunta retórica y en posición final como mdcc).

La función del mdcc de la variante corta sin negación (icierto ?) surge en América antes que en España; concretamente, en el siglo XIX, casi al mismo tiempo que la forma explícita con negación ( ¿ no es cierto?). Por lo que se refiere a la frecuencia de uso, según el corpus, la variante sin negación se utiliza notablemente menos que el mdcc ¿̇no es cierto? En el siglo xix encontramos solamente ocho ejemplos con la variante icierto? (con pausa señalada con coma), más tres ocurrencias con la variante ¿Cierto? (pausa señalada con punto) -como ya hemos mencionado líneas arriba, en el corpus oral de PRESEEA domina la forma corta, por lo cual consideramos que la baja frecuencia de uso puede atribuirse al CDH, corpus escrito, basado principalmente en obras literarias. En el siglo $\mathrm{xx}$, encontramos en total 44 ejemplos con el mdcc ¿̨cierto? (pausa señalada con coma), más 82 ocurrencias con pausa señalada mediante punto; sólo por el afán de comparar, destaquemos que en el siglo xx, en España, hay apenas nueve ocurrencias con esta variante. 
La difusión geográfica de “¿no es cierto?" y “ ¿cierto?" en Hispanoamérica

Antes de pasar a la síntesis de los resultados, merece la pena observar la repartición de los marcadores discursivos dentro de la América hispanohablante, reflejada en las Tablas 5 y 6 , que ofrecen información acerca de la frecuencia de uso de $\dot{i}$ no es cierto? y icierto? con base en los datos del CORPES, representativo del siglo Xxi. Dado que la estructura ¿no es cierto? es el indicador de la función de mdcc de cierto, empezamos con esta forma:

\section{TABLA 5}

Distribución geográfica del mdcc “¿no es cierto?" en el siglo XXI (CORPES)

\begin{tabular}{lcc}
\hline País & Frecuencia absoluta & Frecuencia relativa \\
\hline Perú & 17 & 2.48 \\
Argentina & 50 & 2.40 \\
Colombia & 39 & 2.21 \\
Chile & 31 & 2.08 \\
México & 58 & 2.01 \\
Paraguay & 8 & 1.70 \\
Cuba & 13 & 1.37 \\
España & $\mathbf{1 0 8}$ & 1.25 \\
Guatemala & 4 & 1.11 \\
Costa Rica & 2 & 0.81 \\
Bolivia & 4 & 0.73 \\
Uruguay & 3 & 0.62 \\
Nicaragua & 2 & 0.55 \\
Honduras & 1 & 0.40 \\
Venezuela & 5 & 0.37 \\
República Dominicana & 1 & 0.18 \\
\hline
\end{tabular}

El marcador discursivo ¿̨no es cierto? está presente en 15 países hispanoamericanos. La mayor difusión se da en Perú, luego en Argentina y, por último, en Colombia. Si comparamos la frecuencia relativa de estos países con la de España, vemos que, a todas luces, el mdcc ¿̇no es cierto? se utiliza más en el español americano. 
En cuanto al mdcc $\underset{i}{ }$ cierto?, encontramos los siguientes datos:

\section{TABLA 6}

\section{Distribución geográfica del mdcc "¿cierto?" en el siglo XXI (CORPES)}

\begin{tabular}{lcc}
\hline País & Frecuencia absoluta & Frecuencia relativa \\
\hline Colombia & 82 & 4.66 \\
Perú & 18 & 2.63 \\
Chile & 38 & 2.55 \\
México & 56 & 1.94 \\
Guatemala & 6 & 1.66 \\
Venezuela & 11 & 0.82 \\
Costa Rica & 2 & 0.81 \\
Cuba & 7 & 0.74 \\
Estados Unidos & 2 & 0.70 \\
Panamá & 1 & 0.60 \\
Argentina & 2 & 0.09 \\
España & $\mathbf{0}$ & $\mathbf{0 . 0 0}$ \\
\hline
\end{tabular}

En comparación con el mdcc $\dot{i}$ no es cierto?, la variante abreviada ¿icierto? está presente en menos países. Predomina en Colombia y la siguen Perú y Chile. Recordemos que la mayoría de los estudiosos, al señalar la función de marcador discursivo de cierto, mencionan justamente estos países (cf. supra "Estado de la cuestión"). Curiosamente, según los datos del corpus, la variante abreviada no aparece en textos peninsulares. Por tanto, nuestra hipótesis según la cual la función de mdcc de cierto es una característica del español americano se confirma una vez más.

\section{Conclusiones}

Según se desprende del análisis, las dos estructuras principales con la función de mdcc son las formas ino es cierto? y icierto? en posición final del enunciado. Ambos marcadores parecen haberse desarrollado por vías distintas.

La función de mdcc de cierto surge en España, a finales del siglo XVII, en forma de un mdcc explícito con negación (i ino es cierto?). La negación, que conlleva un carácter eminentemen- 
te retórico, junto a la posición final desempeña un papel fundamental en la evolución de este mdcc (pensemos en el mdcc ¿no?). Por ello, es concebible que el mdcc ¿ no es cierto? se desarrollara mediante un cambio de la posición sintáctica de la pregunta retórica ino es cierto que? Destacamos que esta forma aparece en el corpus con mayor frecuencia que la variante abreviada sin negación. Así, de la comparación con los datos del corpus PRESEEA, deducimos que la mayor frecuencia de la forma explícita ¿no es cierto?, frente a la forma corta $\dot{i}$ cierto?, se debe, probablemente, al carácter escrito del corpus $\mathrm{CDH}$. La forma evidentemente oral ¿no cierto?, salvo en dos casos, no aparece en este corpus.

Por lo que se refiere a su variante corta sin negación, el mdcc icierto? surge primero en América en el siglo XIX. El análisis confirma que esta forma apenas se da en España (ninguna ocurrencia, según el CORPES). Las pocas ocurrencias con esta variante en el corpus $\mathrm{CDH}$ podrían deberse a la influencia hispanoamericana.

Geográficamente, el mdcc ¿ino es cierto? tiene sus orígenes en el español europeo. Sin embargo, según se infiere del análisis cuantitativo, el uso de este marcador discursivo es hoy más característico del español americano que del peninsular. Mediante el análisis hemos podido ver que actualmente se utiliza en todos los países hispanoamericanos y, con mucha menos frecuencia, también en España. En cambio, el mdcc icierto? se mostró ya desde sus principios como una innovación hispanoamericana. A diferencia de ¿̇no es cierto?, el mdcc ïcierto? no se utiliza en la Península.

Hemos visto que la función de control de contacto surge de las preguntas retóricas, por lo que se trata de una función posterior. Su desarrollo se divide en tres fases:

1. Pregunta real por inseguridad o falta de información (sin negación, posición inicial o pregunta del interlocutor).

2. Pregunta retórica (con negación). Posición inicial; se refiere a los diferentes tipos de información que le siguen.

3. Control de contacto: pregunta retórica, con frecuencia al margen derecho de una unidad lingüística, sintácticamente independiente; se refiere al propio enunciado, originariamente con negación.

En este sentido, la negación, la posición final de la unidad lingüística y la intención del interlocutor influyen, en gran parte, sobre la función del marcador discursivo de cierto. 
Resumidas las conclusiones principales, en esta última sección merece la pena resaltar los resultados secundarios que no formaban parte de los objetivos principales de este trabajo, pero que son de importancia capital para los futuros análisis del mdcc cierto.

Durante el análisis, hemos notado que el marcador discursivo cierto puede contar con varias microfunciones (de autojustificación, persuasiva, de amenaza, crítica, ironía, etc.) a las que, en el marco del presente estudio, no hemos podido prestar la atención adecuada. Por tanto, la denominación $m d c c$ resultó ser un término generalizado en el cual conviven varios matices distintos, cuyas microfunciones quedan aún por analizar y diferenciar. Además, aparte de las microfunciones ya mencionadas de cierto, sería interesante observar su ámbito de uso con respecto al registro y compararlo con otros marcadores de control de contacto: ¿̇no?, ¿no es así? ¿ंverdad?, etcétera.

Por último, sería de gran interés examinar el mdcc icierto? en otras lenguas romances -sobre todo el mdcc çerto portugués-, con la finalidad de indagar si hay coincidencias y paralelismos en su evolución diacrónica y función pragmática.

\section{REFERENCIAS}

\section{Corpus}

$\mathrm{CDH}=$ Instituto de Investigación Rafael Lapesa de la Real Academia Española 2013. Corpus del Nuevo diccionario histórico (CDH) [en línea], http:/ / web.frl.es/CNDHE [consultado el $1^{\circ}$ de agosto de 2018].

CORPES XXI = Real Academia Española: Banco de datos (CORPES XXI) [en línea]. Corpus del español del siglo XXI (CORPES), http://www.rae.es [consultado el 8 de julio de 2018].

PRESEEA 2014-. Corpus del Proyecto para el estudio sociolingüistico del español de España y de América, Universidad de Alcalá, Alcalá de Henares, en http:/ / preseea.linguas.net [consultado el 15 de julio de 2018].

\section{Repertorios lexicográficos}

ASALE = Asociación de Academias de la Lengua Española 2010. Diccionario de americanismos (DAMER), en http://lema.rae.es/damer/ [consultado el 8 de julio de 2019].

Briz Gómez, Antonio, Salvador Pons y José Portolés 2008. Diccionario de partículas discursivas del español, Servicio de Publicaciones de la 
Universidad de Valencia, Valencia, en www.dpde.es [consultado el 8 de julio de 2019].

Fuentes Rodríguez, Catalina 2009. Diccionario de conectores y operadores del español, Arco/Libros, Madrid.

Santos Río, Luis 2003. Diccionario de partículas, Luso-Española de Ediciones, Salamanca.

\section{Referencias bibliográficas}

Azofra Sierra, María Elena y Renata Enghels 2017. "El proceso de gramaticalización del marcador epistémico deverbal sabes", Iberoromania: Revista dedicada a las lenguas y literaturas iberorrománicas de Europa y América, 85, pp. 105-129; doi: 10.1515/iber-2017-0008.

Briz Gómez, Antonio 1998. El español coloquial en la conversación. Esbozo de pragmática, Ariel Lingüística, Barcelona.

Briz Gómez, Antonio 2009. "Notas para el estudio de la relación entre las partículas discursivas y la atenuación”, Acta Universitatis Stockholmiensis. Romanica Stockholmiensia, 27, pp. 67-77.

Christl, JoAснim 1996. "Muletillas en el español hablado", en El español hablado y la cultura oral en España e Hispanoamérica. Eds. Thomas Kotschi, Wulf Oesterreicher y Klaus Zimmermann, Vervuert-Iberoamericana, Frankfurt/M.-Madrid, pp. 117-146.

Cortés, Luis y M. Matilde Camacho 2005. Unidades de segmentación y marcadores del discurso. Elementos esenciales en el procesamiento discursivo oral, Arco/Libros, Madrid.

Fuentes Rodríguez, Catalina 1990. "Algunos operadores de función fática”, Sociolingüistica Andaluza, 5, pp. 137-170.

Fuentes Rodríguez, Catalina 1990a. "Apéndices con valor apelativo", Sociolingüistica Andaluza, 5, pp. 171-196.

Fuentes Rodríguez, Catalina 1992. "Las coordinadas del discurso: cierto y sus derivados", en Actas del IV Simposio Internacional de la Asociación Espanola de Semiótica, Visor, Madrid, pp. 897-907.

Fuentes Rodríguez, Catalina 2014. "Los límites del enunciado", en Estudios de Lingüistica del Español, 35, pp. 143-167.

Galué, Dexy 2002. "Marcadores conversacionales: un análisis pragmático”, Boletín de Lingüística, 18, pp. 27-48.

García Agüero, Alba Nalleli 2016. "Marcadores discursivos indicadores de cortesía de la variedad mexicana. Un enfoque pluricéntrico para su enseñanza de ELE”, E-JournALL, EuroAmerican Journal of Applied Linguistics and Languages, 3, 1, pp. 23-42; doi: 10.21283/2376905X.4.62.

Hidalgo Navarro, Antonio y Cristina Villalba Ibáñez 2016. "Problemas de uso del lenguaje oral en sede judicial. Algunas propuestas de mejora", Revista de Llengua i Dret, Journal of Language and Law, 66, pp. 208-225; doi: 10.2436/rld.i66.2016.2757.

Hummel, Martin 2012. Polifuncionalidad, polisemia y estrategia retórica. Los signos discursivos con base atributiva entre oralidad y escritura, De Gruyter, Berlin-Boston. (Beihefte zur Zeitschrift für romanische Philologie, 374). 
Jakobson, Roman 1981. Ensayos de lingüistica y poética general. Trads. Josep M. Pujol y Jem Cabanes, Seix Barral, Barcelona.

Kluge, Bettina 2011. "Camino de un marcador del discurso: una comparación del español ¿̨abes? con el francés tu sais y el inglés you know", en Marcadores del discurso: de la descripción a la definición. Eds. Heidi Aschenberg y Óscar Loureda Lamas, Iberoamericana-Vervuert, Madrid-Frankfurt/M.

Lewis Vergara, Eileen y Abelardo San Martín Núñez 2018. “¿Cachái? y sus equivalentes funcionales en el habla santiaguina: análisis pragmático y sociolingüístico de los marcadores interrogativos de control de contacto", Literatura y Lingüística, 37, pp. 301-327; doi: 10.29344/0717621x.37.1385.

Martín Zorraquino, M.A. y J. Portolés Lázaro 1999. "Los marcadores del discurso", en Gramática descriptiva del español. T. 3: Entre oración y discurso. Morfología. Dirs. Ignacio Bosque y Violeta Demonte, Espasa Calpe, Madrid, pp. 4051-4213.

Molina, Isabel 2005 "La moda del isabes? en el barrio de Salamanca de Madrid: un análisis sociolingüístico”, en Filología y lingüistica. Estudios ofrecidos a Antonio Quilis, Consejo Superior de Investigaciones Científicas-Universidad Nacional de Educación a Distancia-Universidad de Valladolid, Madrid, t. 1, pp. 1045-1056.

Ortega Olivares, Jenaro 1985. “Apéndices modalizadores en español. Los "comprobativos'”, en Estudios románicos dedicados al profesor Andrés Soria Ortega, Universidad de Granada, Granada, t. 1, pp. 239-255.

Ortega Olivares, Jenaro 1986. "Aproximación al mecanismo de la conversación. Apéndices justificativos”, Verba: Anuario Galego de Filoloxia, 13, pp. 269-289.

Pons, Hernán y José Luis Samaniego 1998. "Marcadores pragmáticos de apoyo discursivo en el habla culta de Santiago de Chile”, Onomázein, 3, pp. 11-25.

Portolés LÁzaro, José 1998. Marcadores del discurso, Ariel, Barcelona.

Rabanales, Ambrosio y Lidia Contreras 1992. "Las muletillas en el habla culta de Santiago de Chile", en Scripta philologica in honorem Juan M. Lope Blanch. Coord. Elizabeth Luna Traill, Universidad Nacional Autónoma de México, México, t. 2, pp. 673-744.

Rodríguez Muñoz, Francisco 2009. "Estudio sobre las funciones pragmadiscursivas de $i n o$ ? y $i$ eh? en el español hablado", RLA. Revista de Lingüística Teórica y Aplicada, 47, 1, pp. 83-101; doi: 10.4067/S071848832009000100005.

San Martín Núñez, Abelardo 2011. "Los marcadores interrogativos de control de contacto en el corpus PRESEEA de Santiago de Chile", Boletín de Filología, 46, 2, pp. 135-166; doi: 10.4067/S0718-93032011000200006. 
